\section{DIRECT LIQUID INTRODUCTION LC-MS OF POLYENE MACROLIDE ANTIBIOTICS: COMMENT ON THE STRUCTURE OF FILIPIN II}

\author{
DUNCAN M. F. EdWARdS \\ Lepetit Research Centre, \\ Merrell Dow Research Institute, \\ Via R. Lepetit 34, \\ Gerenzano (VA), Italy
}

(Received for publication June 28, 1988)

Whereas there have been many reports of the use of electron impact $(\mathrm{EI})^{1 \sim 5)}$, fast atom bombardment (FAB) and field desorption (FD) ${ }^{8 \sim 11)}$ ionization to obtain mass spectral information on polyene macrolides, relatively little has been reported on the use of softer forms of chemical ionization such as direct liquid introduction (DLI). EI-MS of polyenes requires prior chemical derivatization of the many hydroxyl groups present in these molecules if high masses are to be seen. FAB and FD have been found to give molecular ions and some useful high mass fragments with underivatized polyenes, but have been principally applied to pure compounds: coupling of FAB-MS with chromatography is possible, but not yet regularly used in structure analysis. It is thus somewhat surprising that chemical ionization liquid chromatography (LC)MS studies of these antibiotics have not been more widely reported.

Here negative ion DLI mass spectra obtained by LC-MS analysis of a $40 \%$ pure preparation of the antibiotic filipin complex ${ }^{2)}$ are reported. The sample was obtained from Sigma. The analysis was carried out on a Hewlett Packard HP5985B mass spectrometer interfaced with an HP1090L chromatograph via a water-cooled DLI probe (Hewlett Packard commercial version) in which split-flow introduction takes place across a $5 \mu$ orifice in a steel diaphragm. The MS source was held at $250^{\circ} \mathrm{C}, 1$ Torr. HPLC was carried out with a mobile phase of acetonitrile - water $(50: 50)$ and a $25 \mathrm{~cm} \times 4.6 \mathrm{~mm}$ RP-8 Supelcosil column, flow rate $1 \mathrm{ml} /$ minute. Mass spectra for filipins III and II were taken at retention times of 5 and 8 minutes respectively; a minor component filipin IV, an epimer of filipin III, was not resolved from III, whereas the late-eluting trace component filipin I was not detected.

Previous EI-MS data on peracetylated filipins ${ }^{2>}$ suggested that filipin II contains one oxygen atom less than the principal component filipin III, the structure of which has been clearly demonstrated ${ }^{1,2,11}$. NMR study of hydrogenated polyenes ${ }^{11}$ led to the tentative suggestion of one of two possible structures for filipin II: either 1'-deoxy-, or 3-deoxy-filipin III. The mass spectra presented here are in accord with the former structure.

Fig. 1 shows the negative ion spectra of filipins II and III. $\mathrm{M}^{-}$and related $\mathrm{H}_{2} \mathrm{O}$ loss fragments for both molecules may be clearly seen. That $m / z 654$ and 638 were the molecular ions could be confirmed by repeating the analysis with a mobile phase of acetonitrile - aqueous ammonium formate $(50: 50)(1 \mathrm{~g} /$ liter $)$ : under these conditions, virtually identical spectra were obtained apart from the appearance of small $\mathrm{M}+46$ and $\mathrm{M}+28$ ions, attributable to $\mathrm{M}+$ $\mathrm{HCOOH}$ and $\mathrm{M}+\mathrm{HCOOH}-\mathrm{H}_{2} \mathrm{O}$ respectively. Filipin III eliminates a fatty aldehyde (fragmentation "a") to give a series of highly abundant ions starting at $\mathrm{m} / \mathrm{z} 554$; the corresponding loss in filipin II is completely absent. Such a large difference can best be explained by the absence of an oxygen atom at the $1^{\prime}$ position in filipin II. Further confirmation of the $1^{\prime}$-deoxy structure is obtained from the most probable assignment of fragmentation "b" in Fig. 1: the corresponding fragment in filipin II is 16 mass units lower, suggesting that the charged fragment produced from the right hand side of the molecule has lost an oxygen. An alternative assignment of fragmentation " $b$ " - ring breakage at positions 3-4 and 15-16 - would give similar masses for the assigned structures but would be very unlikely to occur if the oxygen at position 3 was lacking. Thus either assignment leads to preference for the $1^{\prime}$-deoxy structure.

DLI negative ion spectra of the polyenes amphotericin B (Sigma 80\%) and nystatin (Sigma) have also been obtained under similar conditions and compared with positive ion FAB spectra of the same samples in a glycerol - $\mathrm{HCl}$ matrix: the FAB data were obtained using a Kratos MS50 spectrometer with DS90 data system and Xe bombardment at $6 \mathrm{KeV}, 0.8 \mathrm{~mA}$ discharge current. Whereas the filipin sample discussed above proved too impure to yield significant $\mathrm{FAB}$ data, FAB was found to give superior molecular 
Fig. 1. DLI negative ion spectra of filipins III (IV) (A) and II (B) obtained by LC-MS of filipin complex.

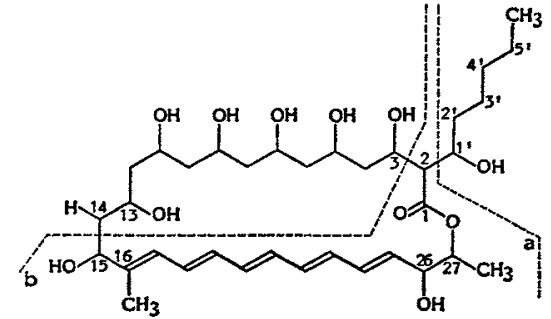

(A)

(\%)
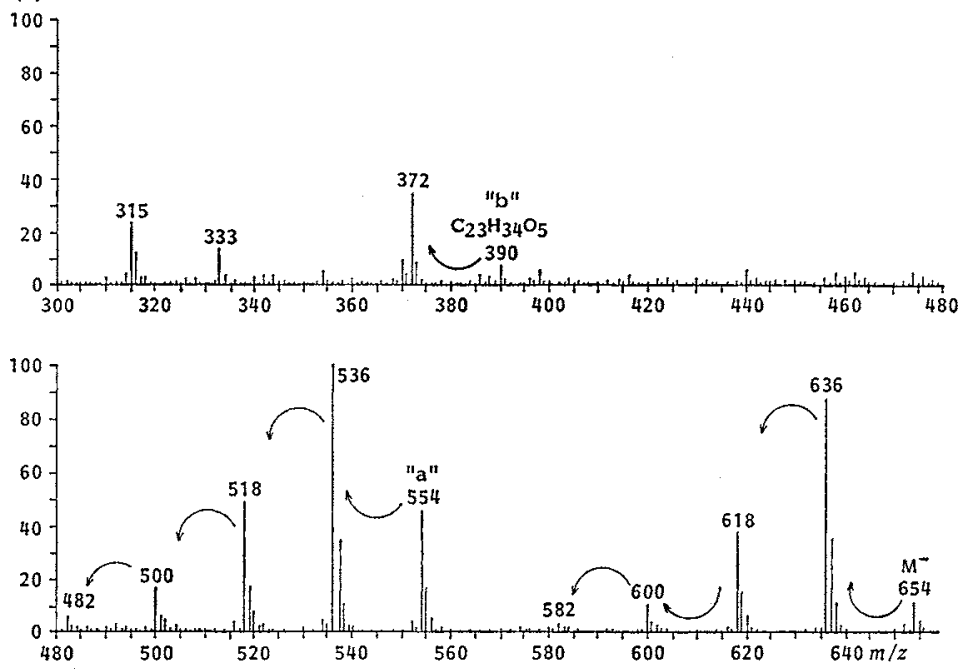

(B)
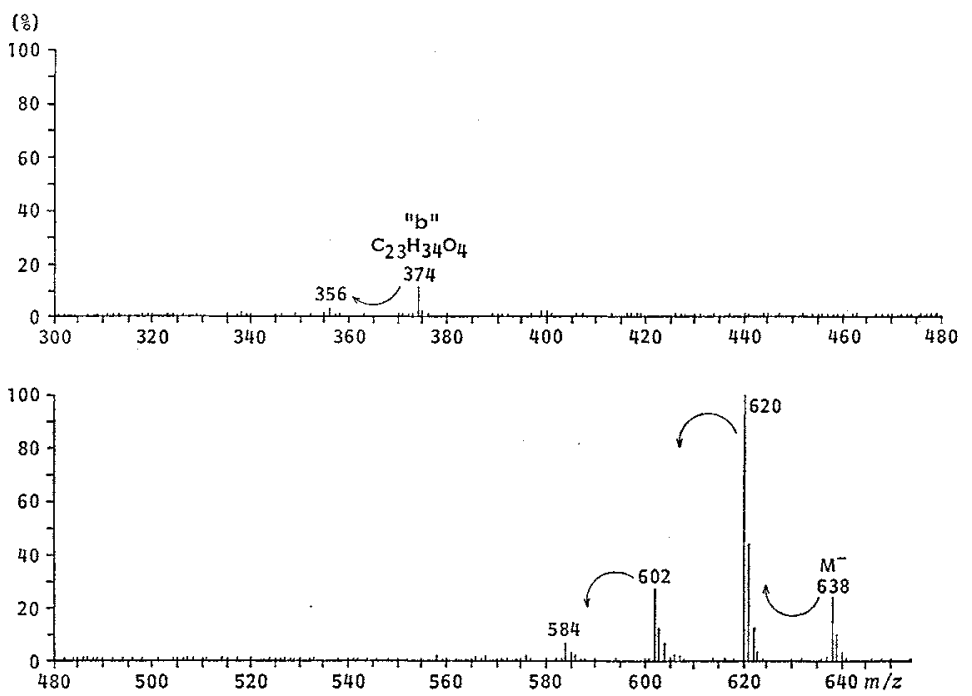

The corresponding peaks are labeled in the accompanying total ion chromatogram (retention timescale in minutes). The illustration of the filipin III structure shows the two principal fragmentations observed, denoted $a$ and $b$. Ion series connected by water losses are indicated by curved arrows. Observation of selected ion chromatograms suggests that the odd mass ions, $m / z 333$ and 315 in the filipin III spectrum are due to a pre-eluting impurity. 
weight information for amphotericin $B$ and nystatin (principal component $A_{1}$ ). These heavire molecules (respective molecular weights 923 and $925)$ readily eliminate the aminosugar mycosamine (myc), and $\mathrm{CO}_{2}$ from a carboxylic acid group, in the mass spectrometer. The negative ion DLI spectra showed ions in the $\mathrm{M}-\mathrm{nH}_{2} \mathrm{O}-$ $\mathrm{CO}_{2}$ series as the highest observable masses, followed by $\mathrm{M}-\mathrm{nH}_{2} \mathrm{O}-$ myc and $\mathrm{M}-\mathrm{nH}_{2} \mathrm{O}-$ myc $-\mathrm{CO}_{2}$, and some lower mass skeletal fragments containing the polyene segment. FAB gave intense ions corresponding to protonated $\mathrm{M}, \mathrm{M}-\mathrm{H}_{2} \mathrm{O}$, and $\mathrm{M}+$ glycerol; weaker ions were observed in the $\mathrm{M}-\mathrm{nH}_{2} \mathrm{O}-$ myc and $\mathrm{M}-$ $\mathrm{nH}_{2} \mathrm{O}-$ myc $-\mathrm{CO}_{2}$ series. However, the lower mass fragment information was clearer in the DLI spectra. The structures of nystatin (principal component $A_{1}$ ) and amphotericin $B^{2,12)}$ differ, apart from the positions of two hydroxyl groups, only in the saturation of a double bond in the polyene segment. The skeletal fragmentations of amphotericin B and nystatin with DLI gave similar profiles in which this two mass unit difference could be readily identified; FAB and DLI information are thus overlapping and complementary.

The value of techniques such as DLI LC-MS should not be underestimated for analysis of polyenes. The example of filipin shows that clear structural and molecular weight information may be obtained for some molecules. Use of both DLI LC-MS and FAB together provides a powerful analytical method which can recognize the presence of novel polyene structures in submilligram quantities of partially purified samples.

\section{References}

1) Golding, B. T. \& R. W. Rickards: The determination of molecular formulae of polyols by mass spectrometry of their trimethylsilyl ethers; the structure of the macrolide antibiotic filipin. Tetrahedron Lett. 1964: 2615 2621, 1964
2) Pandey, R. C. \& K. L. Rinehart, Jr.: Polyene antibiotics. V. Characterization of components of the filipin complex by mass spectrometry. J. Antibiotics 23: 414 417, 1970

3) HaEgele, K.D. \& D. M. Desiderio: The structural elucidation of polyene macrolide antibiotics by mass spectrometry; nystatin, amphotericin B and pimaricin. Biomed. Mass Spectrom. 1: 20 28, 1974

4) SYNAK, R.; J. ZiElińsKI, J. GOlik \& E. BoRowskr: The structure of candidoin, a component of the candidin antibiotic complex. J. Antibiotics 36: 1415 1417, 1983

5) Dornberger, K.; D. VoIGT, W. IhN, J. VoKoun \& H. THRUM: Massenspektroskopische Untersuchungen an Polyenantibiotika. Fragmentierungsverhalten einiger Tetraene. Tetrahedron 32: 3069 3073, 1976

6) Rinehart, K. L., Jr.; J. C. CoOK, Jr., K. H. MAURER \& U. RAPP: Field desorption mass spectra of antibiotics. J. Antibiotics 27: 1 13, 1974

7) Schlegel, R.; H. Thrum, J. Zielinski \& E. BoRowski: The structure of roflamycoin, a new polyene macrolide antifungal antibiotic. $\mathrm{J}$, Antibiotics 34: 122 123, 1981

8) Rinehart, K. L., Jr.: Fast atom bombardment mass spectrometry. Science 218: $254 \sim 260$, 1982

9) Tweit, R. C.; R. C. PANDEY \& K. L. RineHART, Jr.: Characterization of the antifungal and antiprotozoal antibiotic partricin and structural studies on partricins A and B. J. Antibiotics 35: $997 \sim 1012,1982$

10) Sowiński, P.; P. KolodziejCzyK \& E. BorowskI: The structure of amphotericin A. I. Mass spectrometric analysis of dodecahydroamphotericin A. J. Antibiotics 38: 169 174, 1985

11) Pandey, R. C.; N. Narasimhachari, K. L. Rinehart, Ir. \& D.S. Millington: Polyene antibiotics. IV. Structure of chainin. J. Am. Chem. Soc. 94: 4306 4310, 1972

12) Pandey, R. C. \& K. L. Rinehart, Jr.: Polyene antibiotics. VII. Carbon-13 nuclear magnetic resonance evidence for cyclic hemiketals in the polyene antibiotics amphotericin $B$, nystatin $A_{1}$, tetrin $\mathrm{A}$, tetrin $\mathrm{B}$, lucensomycin, and pimaricin. J. Antibiotics 29: 1035 1042, 1976 